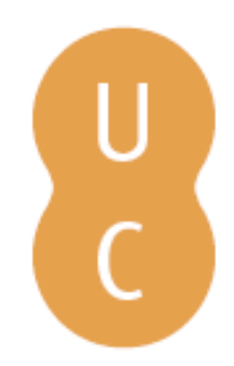

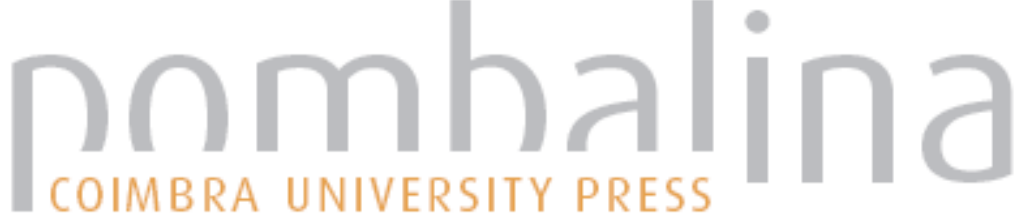

\section{Combates pela imagem na história do século XX: um percurso pessoal}

\author{
Autor(es): $\quad$ Ramires, Alexandre \\ Publicado por: Imprensa da Universidade de Coimbra \\ URL \\ persistente: \\ URI:http://hdl.handle.net/10316.2/31645 \\ DOI: \\ DOI:http://dx.doi.org/10.14195/978-989-26-0199-1_35
}

Accessed : $\quad$ 26-Apr-2023 11:00:31

A navegação consulta e descarregamento dos títulos inseridos nas Bibliotecas Digitais UC Digitalis, UC Pombalina e UC Impactum, pressupõem a aceitação plena e sem reservas dos Termos e Condições de Uso destas Bibliotecas Digitais, disponíveis em https://digitalis.uc.pt/pt-pt/termos.

Conforme exposto nos referidos Termos e Condições de Uso, o descarregamento de títulos de acesso restrito requer uma licença válida de autorização devendo o utilizador aceder ao(s) documento(s) a partir de um endereço de IP da instituição detentora da supramencionada licença.

Ao utilizador é apenas permitido o descarregamento para uso pessoal, pelo que o emprego do(s) título(s) descarregado(s) para outro fim, designadamente comercial, carece de autorização do respetivo autor ou editor da obra.

Na medida em que todas as obras da UC Digitalis se encontram protegidas pelo Código do Direito de Autor e Direitos Conexos e demais legislação aplicável, toda a cópia, parcial ou total, deste documento, nos casos em que é legalmente admitida, deverá conter ou fazer-se acompanhar por este aviso.

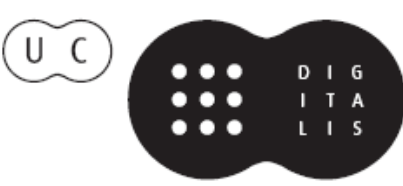


Maria Manuela Tavares Ribeiro

Coordenação

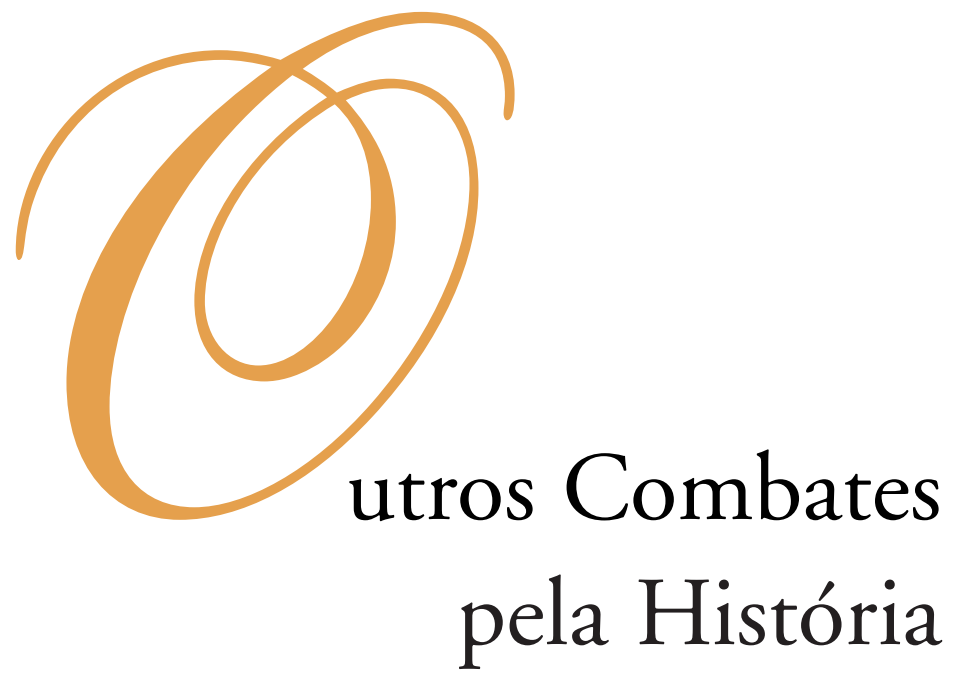




\section{COORDENAÇĀO EDITORIAL}

Imprensa da Universidade de Coimbra

Email: imprensauc@ci.uc.pt

URL: http://www.uc.pt/imprensa_uc

Vendas online: http://livrariadaimprensa.com

\section{CONCEPÇÃO GRÁFICA}

António Barros

\section{ORgANIZAÇĀO DOS TEXTOS}

Isabel Maria Luciano

Marlene Taveira

PRÉ-IMPRESSÃO

António Resende

Imprensa da Universidade de Coimbra

EXECUÇÃO GRÁFICA

SerSilito • Maia

ISBN

978-989-26-0041-3

DEPósito LEGAL

OBRA PUBLICADA COM O APOIO DE:

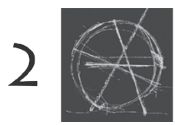

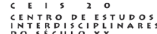

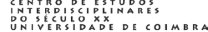

FCT Fundação para a Ciência e a Tecnologia

MINISTÉRIO DA CIÊNCIA, TECNOLOGIA E ENSINO SUPERIOR Portugal

Programa Operacional Ciência, Tecnologia, INOVAÇĀo DO QUADRo COMUNITÁRIO DE APOIO III

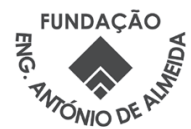

C JULHO 2010, IMPRENSA DA UNIVERSIDADE DE COIMBRA 
Maria Manuela Tavares Ribeiro

Coordenação

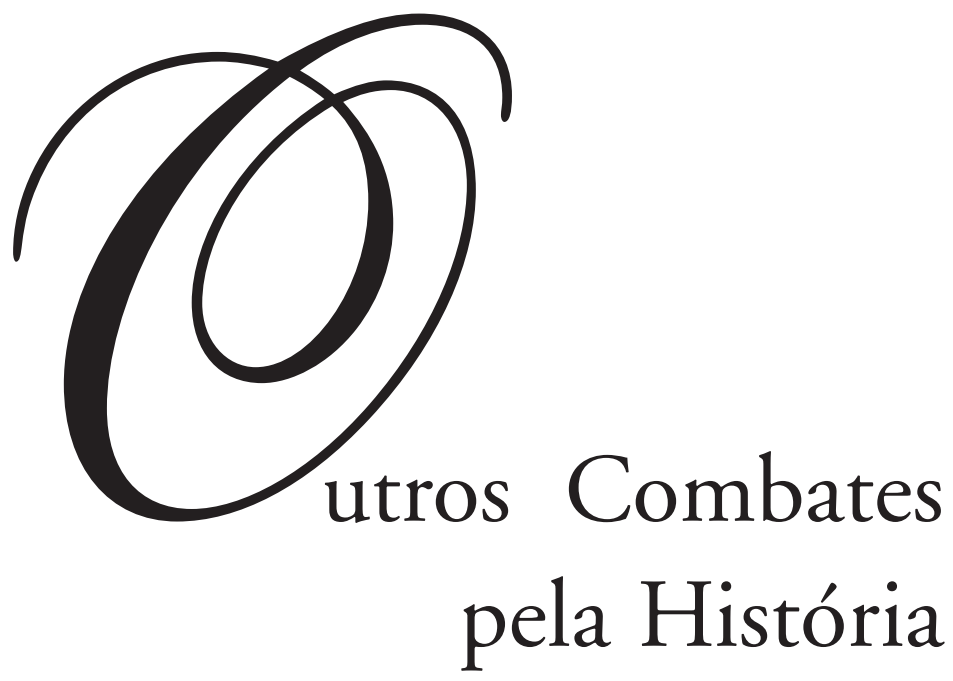

- colmbra 2010 
História, Ideias e Artes 


\section{Alexandre Ramires}

\section{COMbATES PELA IMAGEM NA HISTÓRIA DO SÉCULO XX - UM PERCURSO PESSOAL}

Terão as imagens um papel a desempenhar na investigação histórica? Poderão ser consideradas como uma fonte documental que acrescenta uma nova dimensão aos registos do passado? E como se dá a interacção com a memória individual e colectiva? Poderá o recurso à imagem fornecer à memória documentação referenciada, que lhe limite a deriva para zonas de penumbra que alteram a percepção da realidade?

Para dar a conhecer as metodologias que utilizei para responder a estas questôes passarei a relatar algumas das actividades que desenvolvi nas últimas décadas, com o objectivo de atribuir à imagem a relevância que julgo poder ter para o conhecimento, reconhecendo a sua especificidade para que possa ser devidamente enquadrada e rentabilizada.

Desde a infância que a imagem exerceu sobre mim um fascínio e sedução que me fizeram utilizá-la como fonte importante de conhecimento. Numa primeira fase foi a banda desenhada, com os Mundos de Aventuras, os Zorros, os Ciclones e os Tintins, com histórias que frequentemente interagiam com a História e a Ciência, fornecendo a pouco e pouco a consciência dos momentos únicos que estávamos a viver, como a corrida para a Lua, a descoberta do DNA ou a tectónica de placas, não esquecendo as utopias sociais que pareciam inevitáveis. Ora tudo isto começava a ser visualizado através de publicações periódicas e revistas. As utopias e conceitos abstractos podiam ser associadas imagens, o que possibilitava um ritmo mais acentuado de progressão na integração de conhecimentos, e sobretudo a interligação de várias áreas de saber específico. As peças do puzzle da racionalização e interpretação da realidade compunham sínteses que nos faziam crescer.

A par da Banda Desenhada, as colecções de cromos também tiveram o seu papel. Como não recordar a História de Portugal da Agência Portuguesa de Revistas, que ainda hoje contamina o imaginário de muitos portugueses sobre a sua História. A prova disto podemos encontrá-la no filme Non, de Manoel de Oliveira, em que há planos que parecem decalcados directamente.

Mas a tecnologia que inundou a sociedade de imagens foi sem dúvida a televisão, substituindo aos poucos muitos dos hábitos culturais, e os imaginários a eles associados, por outras referências que mais atordoaram do que ensinaram. Embora os horários de emissão nos primeiros tempos fossem muito limitados, comparados com o que são hoje, a novidade era suficientemente forte para desviar os olhares. 
Os primeiros conteúdos televisivos que me chamaram a atenção foram as séries de aventuras, como Robin dos Bosques, ou as animações do Gato Félix, do Rato Mickey, e as da Warner como o Zé Colmeia, o D. Quixote e o Pepe Legal, entre outras, e, como não podia deixar de ser, os jogos de Futebol da Taça dos Campeões Europeus e da Taça das Taças. Nesta primeira fase, nos inícios dos anos 60, a televisão tinha sobretudo uma função de entretenimento.

O outro grande fornecedor de imagens era sem dúvida o Cinema, com as matinés dos fins de semana, ou as soirées, que se frequentavam assiduamente durante as férias e, por vezes, a meio da semana. As sessōes de cinema eram efectuadas em salas de dimensões apreciáveis, sobretudo se comparadas com as que as vieram substituir. Pelo menos na província, eram constituídas por dois filmes, a estreia local e um filme mais antigo que circulava até esgotar a licença de exibição de cinco anos que então vigorava.

Este registo de exibição cinematográfica permitiu o preenchimento dos imaginários do cidadão nacional com o essencial das produçôes cinematográficas do mundo ocidental.

São exemplos: os Westerns do cinema americano e não só, os filmes italianos, desde os Fellinis, Rosselinis e Antonionis ao peplum e ao western Spaguetti, o cinema espanhol com a Marisol e o Joselito, ou o Cantiflas do México, sem esquecer o cinema português dos anos trinta e quarenta, por vezes com propaganda à mistura, como foi o caso de "O Chaimite» de Brun do Canto, ou com os noticiários que antecediam algumas exibições. Em suma, com o cinema os imaginários iam circulando à escala global e antecipavam o que é hoje a oferta multifacetada de produtos visuais.

Contudo, em actividades culturais que integravam o cinema como objecto, actuavam os Cineclubes que alargavam o âmbito dos produtos disponíveis para documentos com outro valor cultural e político. Assim, eram visionados alguns autores proibidos e produzidas, no âmbito do cinema amador nacional, algumas obras que exerciam a autonomia possível no regime de então. Foi por esta via, com recurso aos formatos de $8 \mathrm{~mm}$ e Super8, e por vezes em $16 \mathrm{~mm}$, que foram recolhidas imagens que podem recuperar o ambiente destes anos em Portugal. Infelizmente o trabalho de inventariação e recolha destes documentos não está feito. O super 8 também foi utilizado na luta política para projectar ao domicílio filmes proibidos como o "Couraçado Potemkine» de S. Eisenstein, entre outros.

Nos finais dos anos 60 e inícios de 70, a televisão começa a incorporar produções de alto valor cultural e cientifico, sobretudo por iniciativa da BBC, com uma série de nome "Civilization" sobre História de Arte, concebida e apresentada por Kenneth Clarke, curador do Museu Britânico e que aconselhava Calouste Gulbenkian nas aquisições para a sua colecção. Logo a seguir é produzida uma outra, desta vez sobre História da Ciência, "Ascent of Man», com autoria de J. Bronowski. São séries de uma enorme qualidade, ainda hoje mantêm toda a sua relevância. Infelizmente a lógica de usar, ver e esquecer fez com que sejam hoje praticamente desconhecidas. Estas duas séries passaram na televisão portuguesa ainda antes do 25 de Abril. Por cá, o que se produzia eram os trabalhos de António Manuel Baptista e Eurico da Fonseca nas ciências, os de Vitorino Nemésio, Hermano Saraiva e David Mourão Ferreira nas humanidades, e os de recolha de cultura popular levada a cabo por Michel Giacometti, com a série "O Povo que Canta». 
Em 1975, no âmbito de um projecto apresentado por Michel Giacometti ao Ministério da Educação para integrar o Serviço Cívico Estudantil, o «Plano Trabalho e Cultura», tive a oportunidade de utilizar a fotografia e contactar com os primeiros vídeos portáteis para registar estas realidades que estavam em fase de desaparecimento acelerado, também por influência da televisão. Este projecto deu origem a alguns trabalhos académicos, à criação do Museu do Trabalho, em Setúbal, mas sobretudo permitiu-me, passados trinta anos, devolver as imagens registadas ao lugar onde tinham sido captadas e verificar que a recolha de imagens, atenta às transformações a ocorrer, tem um valor elevado para a memória da Cultura Local.

Este primeiro contacto com o registo em vídeo antecipou o aparecimento de tecnologias que permitiam armazenar um volume suficientemente elevado de documentos em imagem que iriam, a prazo, tornar possível associar, a praticamente a todos os conceitos fundamentais das mais diversas áreas e níveis de conhecimento, imagens com conteúdo capaz de os visualizar.

Logo a seguir envolvi-me em actividades de dinamização cultural que utilizavam o Cinema como instrumento, com a projecção de filmes em $16 \mathrm{~mm}$, nomeadamente com a exibição de títulos como "Las Hurdes" de Luís Bunuel, ou os filmes de Charlie Chaplin e Buster Keaton. Nestas actividades tive a oportunidade de trabalhar de perto com Joaquim Namorado, poeta e matemático, nome incontornável na actividade cultural associada à luta política.

Para a exibição de filmes de ficção e documentários com conteúdos científicos recorria-se às filmotecas das embaixadas, nomeadamente à da França, para os filmes de ciência, e à do Canadá para os filmes de animação de Norman MacLaren, entre outros.

$\mathrm{Na}$ sequência destas actividades integrei o Centro de Estudos Cinematográficos da Associação Académica de Coimbra, onde fiz parte da direcção. A primeira prioridade, para além da organização dos ciclos de cinema, foi o registo cinematográfico, no formato Super8, dos acontecimentos que nos pareciam mais interessantes: Assembleias Magnas, campanhas eleitorais e actividades culturais.

Por esta altura o grande evento cinematográfico em Portugal era o Festival de Cinema da Figueira da Foz, que tinha particularidades únicas de acesso à produção cinematográfica mundial. São vários os exemplos: a presença de realizadores importantes à escala mundial no que respeita ao que se fazia de realmente novo no Cinema; a possibilidade de assistir às estreias dos últimos filmes portugueses, que faziam por estar prontos para ali poderem estrear; o contacto com filmes que dificilmente poderiam voltar a ser visionados, tendo em conta que o vídeo doméstico ainda não existia e, finalmente, as facilidades de estadia e participação que eram proporcionadas. Em suma, dez dias em Setembro em que se via e aprendia mais do que em todo um ano de idas ao Cinema.

Não posso aqui deixar de referir um filme que vi na Figueira em 1981, na mesma altura que conheci o seu autor, e que muito me influenciou nos trabalhos que viria a desenvolver nos anos seguintes. Trata-se de «Diálogos com uma mulher desaparecida» de Leo Hurwitz (1909-1991), aliás objecto da minha única incursão na crítica cinematográfica com um artigo publicado na revista Vértice. Este filme viria a ganhar o prémio do Festival de Leipzig para o filme documental, em 1981, e o prémio do FIPRESCI (federação internacional de critica cinematográfica), como também já tinha 
acontecido na Figueira. De que trata, afinal? É uma montagem/narrativa com documentos cinematográficos de eventos importantes no século vinte, que vão da guerra civil de Espanha até aos movimentos pelos direitos cívicos nos Estados Unidos, recolhidos por Leo Hurwitz e pela sua mulher Peggy Lawson, que tinha como profissão a montagem de filmes. Quando Peggy morreu, em 1971, Hurwitz, já com idade avançada, 72 anos, começa a construir uma narrativa em imagem, com filmes obtidos e vividos em conjunto, tendo como resultado um registo único de interacção entre Memória filmada e História. Foi um belo exemplo de como o registo de vivências, pelas técnicas que começavam a estar acessíveis, poderiam originar obras relevantes. Infelizmente é um filme que não se encontra hoje disponível no mercado.

$\mathrm{Na}$ sequência destas experiências vi-me envolvido na organização de ciclos de cinema português; foi a primeira ocasião de regresso às salas do filme de Manoel de Oliveira "Amor de Perdição», depois de uma polémica exibição televisiva em quatro episódios.

O projecto seguinte foi reeditar, em Coimbra, um Festival de Filme Amador, com alguma ressonância Internacional. Foi o FIFAC, que contou uma vasta participação internacional, e que incorporou no seu júri nomes relevantes como Alves Costa, à época decano dos críticos de Cinema, e a escritora Ilse Losa. Começou no mesmo ano dos Encontros de Fotografia, mas foi interrompido depois de três anos de existência devido às intermitências que os ciclos na participação estudantil na Associação Académica sempre provocam.

Estamos num tempo em que surgem, para o cidadão comum, duas grandes revoluçôes tecnológicas: a do registo em vídeo, e a da informática, embora esta última ainda não tivesse capacidade para armazenar conteúdos visuais que o registo em vídeo já permitia. A minha opção foi claramente pelo vídeo. Só recentemente, e com o aparecimento dos DVD's, os computadores o conseguiram superar; foram precisos mais de vinte anos para isso se verificar. Entretanto, ainda foi possível efectuar alguns trabalhos de interacção com as várias tecnologias em presença — vídeo, computador e super8 - como foram os filmes para as peças de Teatro do CITAC e da Bonifrates, D. Duardos e Ibéria Sector 5.

Com o aparecimento da tecnologia vídeo abriram-se algumas oportunidades no mundo do ensino, tanto na formação de professores como na disponibilização de conteúdos visuais para uso em contexto educativo. Assim, na Faculdade de Ciências e Tecnologia da Universidade de Coimbra, e para utilização na formação prestada no ramo educacional, foi criado um laboratório de Micro-Ensino, que tinha como função registar uma aula simulada dos candidatos a professores, identificar e analisar comportamentos e propor as melhores soluçôes. Nesta actividade assegurei a operacionalidade dos equipamentos. Noutra instituição, o Instituto Português de Ensino à Distância (antecessor da Universidade Aberta), prestei algumas colaboraçôes.

O tempo era de possibilidades vastas para a utilização da imagem. Finalmente, a capacidade de dominar os conteúdos da televisão para uma utilização com conta, peso e medida, de controlar o ritmo da linguagem cinematográfica, de escolher, testar e partilhar as imagens com os conteúdos abstractos do conhecimento. Estava-se no momento de começar o trabalho de sistematização, de arquivo e disponibilização das imagens, nesta civilização que já as produzia em quantidade e qualidade, mas que não as tratava nem disponibilizava para as aprendizagens que só poderiam ter lugar na 
Escola, com uma abrangência que pudesse aumentar o número de conteúdos a ensinar e possibilitar a sua inter penetração para sínteses cognitivas que dessem uma nova coesão ao conhecimento.

Como concretizar esta convicção? A oportunidade surgiu no exercício da minha profissão de professor de Física do Ensino Secundário em Portimão, na Escola Secundária de Manuel Teixeira Gomes. Numa primeira fase, rentabilizar as gravações que já tinha efectuado quando ensinei em Coimbra e em Pombal, tratá-las para o ensino da Física e da Química e depois alargar a actividade a outras áreas de conhecimento, tarefa que me foi facilitada ao integrar o Conselho Directivo para criar e gerir um arquivo de vídeo para uso escolar, que passado algum tempo já tinha níveis elevados de utilização e que conseguia responder a solicitações de outras escolas e instituições. Caminhos novos se abriam.

No começo dos anos 90 fui convidado para integrar o Centro de Recursos de Professores da Direcção Regional de Educação do Centro, com as funções de responsável pelo sector de Tecnologia Vídeo, continuando, durante quatro anos, a desenvolver as técnicas e as disponibilidades que o avolumar do arquivo de vídeo me permitiam, ou seja, responder com propostas de imagens para utilização pedagógica nas mais variadas áreas de conhecimento e níveis de ensino. Neste sentido, desenvolvi técnicas inovadoras para o tratamento e utilização do vídeo em contexto educativo e orientei acções de formação para professores para lhes dar a conhecer as novas oportunidades que se abriam, para além de os alertar para a ilusão de conhecimento que o mero contacto com as imagens gera, para a necessidade de fazer a ponte com os saberes já estabelecidos em áreas curriculares, sem esquecer a avaliação da eficácia da transmissão de conhecimentos por esta via, a fim de aferir a eficácia das imagens utilizadas. Esta actividade foi interrompida, na sua dimensão institucional, quando, na sequência da diminuição do número de professores destacados ordenada pelo Ministério de Manuela Ferreira Leite, fui impedido de continuar a desempenhar estas funções.

Em 1996 fui convidado para dirigir e implementar o que seria o arquivo de imagem da Câmara de Coimbra, — que viria a ter a designação de Imagoteca Municipal de Coimbra - e para desenvolver uma actividade que consistia na criação de eventos com dimensão visual e ao mesmo tempo organizar e disponibilizar os fundos de imagens que fosse possível reunir. Naturalmente, estas funçōes implicaram uma investigação sistemática sobre a História da cidade de Coimbra, as suas transformações e os seus protagonistas, e a identificação das situações e momentos em que Coimbra teve um real protagonismo na cultura, na ciência e na política, de modo a tornar possível a descoberta de fontes documentais que fizessem prova dessa relevância. Foram quatro anos de incessante actividade, num cruzamento permanente de documentos, que permitiu salvar milhares de imagens e disponibilizá-las através de exposições com o auxílio das tecnologias que, nesses tempos trepidantes de inovação tecnológica, foi possível utilizar.

Mas passemos a alguns exemplos. Nessa altura chegou à Imagoteca um volume apreciável de negativos proveniente do espólio de Fernando Marques, o Formidável, que recentemente tinha falecido. Identificar o legado era uma tarefa apreciável. Estava fora de questão passar a papel as imagens em negativo, pelo volume de trabalho que significava, não sendo por esta via possível identificar o conteúdo do fundo em tempo útil para o tornar visível, justificando assim os custos necessários à sua conservação. 
Por feliz coincidência tinha surgido no mercado uma máquina que permitia, por via electrónica, ver em positivo, num ecran de televisão, o conteúdo dos negativos (a FV-10, da Fuji): bastava carregar num botão. Foi assim possível visualizar vários milhares de negativos e verificar que este fundo era único pela amplitude e variedade dos temas e momentos abrangidos. Daqui saiu material para várias exposições, quer realizadas em Coimbra, quer fora, por exemplo: «Estado do Tempo» nos Encontros da Imagem em Braga; "Memórias das Oposições», em Coimbra; "Homenagem a Fernando Marques» feita pelo CNID (Clube Nacional de Imprensa Desportiva), na Figueira da Foz; "Há horas que são de todos", (sobre os acontecimentos do 25 de Abril em Coimbra); "Coimbra, 17 de Abril de 1969»; "Olhares Cruzados», sobre a selecção Nacional no Mundial de Futebol de 1966; «Homenagem aos Internacionais A da A.A.C»; "Carris», sobre Eléctricos e Comboios em Coimbra; "Obras», sobre transformações físicas no tecido urbano de Coimbra, entre outras. Este Fundo regista quarenta anos de História Local e Nacional de uma forma exemplar.

Ao desenvolver estas actividades deparei com algumas questôes teóricas importantes, como a de avaliar o grau de credibilidade e rigor a que se pode aspirar na interpretação das imagens e o que fazer para as integrar na memória, uma vez que esta é um processo dinâmico que incorpora de uma forma inconsciente muitos elementos estranhos. Ora, se as imagens forem devidamente enquadradas e certificadas como fontes documentais seguras, poderão ser instrumento para a tomada de consciência das metamorfoses a que estão sujeitas pela memória, e contribuir para uma melhor aproximação à realidade.

Tentei organizar a utilização das imagens ao elaborar cronologias com narrativa cinematográfica, para acrescentar uma possibilidade de arrumação das imagens capaz de reconstituir visualmente momentos e eventos de relevância social, cultural e politica.

Como exemplos de cronologias visuais elaboradas para o século vinte, posso referir: «Imagens da República», elaborada com o professor António Pedro Vicente; «Cliché Garcez», sobre o fotógrafo Arnaldo Garcez, do Corpo Expedicionário Português, na 1a Grande Guerra; "Missão Botânica, Angola 1927», com as imagens obtidas pelo professor Luís Carrisso; "Arcindo Madeira, um Abraço em Traço», sobre os seus desenhos; «Memória das Oposições, 1945-1973», elaborada com a Doutora Heloisa Paulo; "A Alta que Falta», com uma reconstituição visual do que foi a Alta de Coimbra; "A construção da Ponte de Sta Clara, em 1954»; "A crise Académica de 1969»; "25 por 25 em Abril um Quartel Depois», onde se fez a reconstituição do que aconteceu no 25 de Abril de 1974 em Coimbra.

A primeira cronologia em imagem que concretizei começou a ser feita, ainda na década de 70 do séc. XX, com a organização das fotografias da secção fotográfica da A.A.C., para reconstituir os acontecimentos da Crise Académica de 1969. Foram depois utilizadas para as confrontar com as memórias de alguns dos protagonistas, o que me permitiu entender algumas características importantes sobre a natureza da memória, seus apagamentos, amplificações e alteraçóes.

Para além disto impunha-se continuar o registo do quotidiano, já com recurso ao vídeo e à fotografia em $35 \mathrm{~mm}$ : espectáculos, conferências e celebraçōes, com uma filosofia de registo semelhante à da Associação Europeia de Arquivo de Filmes "Inédits», que adopta a necessidade de salvaguardar e conservar os registos visuais feitos por 
cidadãos comuns, de modo a que no futuro exista uma recolha diversificada de imagens capazes de fornecer objectos de estudo, até para temas que hoje ainda não conseguimos antecipar.

Por esta altura foi criado o CEIS20, e foi natural enquadrar algumas destas actividades nas iniciativas públicas que o Centro começava a desenvolver, como foram as comemorações dos quarenta anos da campanha eleitoral de 1958, a exposição "Memórias das Oposiçōes», as eleiçôes em Coimbra (1945-1973).

Estas actividades, e as descobertas de fundos fotográficos antigos, fizeram-me tomar a consciência de que os momentos mais importantes a investigar eram os do inicio da imagem fotográfica, nos meados do séc. XIX, provavelmente as imagens que mais se justifica proteger para o futuro. E, para minha surpresa, Coimbra e a sua Universidade tinham aí desempenhado um papel importante. Naturalmente, estas investigaçōes traduziram-se em exposições sobre a fotografia antiga de Coimbra: "Revelar Coimbra» e "Passado ao Espelho» - que contaram com catálogos que ajudaram a colocar Coimbra na História da Fotografia de Portugal.

A partilha de imagens leva naturalmente à descoberta de novas, que foram aos poucos recuperando e implantando uma visão fotográfica do século vinte, com autorias que foram descobertas e investigadas, por exemplo: os trabalhos fotográficos de Belisário Pimenta, Afonso Rasteiro, Luís Carrisso, Jacinto Araújo e Silva e Fernando Marques, ou de fotógrafos nacionais como: Aurélio da Paz dos Reis, Benoliel, Marques de Abreu ou Domingos Alvão.

As minhas funções como Coordenador do Arquivo de Fotografia do Porto permitiram-me alargar o conhecimento sobre a produção fotográfica Nacional, e naturalmente fazer comparações com outros fundos que já conhecia, abrindo-me possibilidades de leituras das e nas imagens que levaram a algumas descobertas.

A actividade científica do CEIS20 permitiu o exercício de investigaçōes, que deram origens a produções, como as Exposições «Fixar a Universidade» sobre a Universidade de Coimbra na comemoração do $3^{\circ}$ Centenário de Camões, ou «Brasil-Portugal» sobre a $1^{\text {a }}$ travessia do Atlântico Sul, por Gago Coutinho e Sacadura Cabral, ou a «Fotobiografia de António José de Almeida».

Todos estes trabalhos desenrolaram-se como se de Combates se tratasse, porque me parece que a imagem ainda não tem o papel que deveria ter, até por algumas publicações não incorporarem condições necessárias para uma visualização adequada das imagens. Não é claro se existe espaço para a elaboração de narrativas visuais com identidade ou se as imagens apenas se destinam a ilustrar textos. Se as publicaçôes não dispuserem de características capazes para incorporar a imagem com a qualidade necessária, não poderemos ganhar para a imagem um lugar equiparável ao do texto escrito e, como resultado, uma interacção equilibrada e produtiva entre os dois registos.

Termino com um esclarecimento sobre o título desta comunicação. Inicialmente deveria ser uma comunicação conjunta com o Professor António Pedro Vicente sobre Fotografia e História mas, por razões de saúde do nosso amigo, tal não foi possível. Quanto se tornou claro que seria eu a fazê-la sozinho, pensei abordar um tema que me é caro, o do uso da imagem na relação entre Memória e História, mas depois julguei ser este apenas parte dum Combate mais geral pelo uso da Imagem, que seria importante fixar num texto sem imagens. 
Série

Documentos

Imprensa da Universidade de Coimbra

Coimbra University Press

2010

- U

C • 